\title{
Research on the Digital Music Generating Model based on the Music Mapping and Visualization Technology
}

\author{
Sui Wu \\ Hunan City University, \\ Yiyang,Hunan,413000 China
}

\begin{abstract}
In this paper, we conduct research on digital music generating model based on the music mapping and the visualization technology. Music creation, composers in the form of the structure of the organization in following some specific development logic, conform to the aesthetic taste of the audience is widely accepted by the audience for the work of one of the important means. Overall arrangement in music works into a similar structure with the Chinese characteristics in the logic of the thinking, the contemporary Chinese composers in formal structure organization of his work is very common means of creation, show the characteristics of the structure of music works quantity is very large. Accordingly, we propose the enhanced digital music generating that will be innovative.
\end{abstract}

Keywords- Digital Music, Generating Model, Music Mapping, Visualization Technology.

\section{Introduction}

Music creation means the artist formed in the mind of the "structure" by various elements of music art form. In the process of modern music creation, only by simple skills and logic composing music is not comprehensive enough. In the process of its formation and complete, music creation of psychological factors is not allow to ignore, it is sometimes carried more than people thought in the works of music a kind of inspiration, more probably, it make the music works to get a double sublimation of reason and sensibility. Music creation is the major factors of imagination, assumptions, and others. Based on the literature review, we could summarize the issues as the follows. (1) In the process of thought, logic is a direct effect on the object of music creation it is also through the brain's logical thinking reflected in the music creation.
Imagine logic to have a certain universality of accumulating knowledge and the professional skills, and imagine the logic of thinking in a way that shows the rationality of the music works. (2) Anything in real life, the occurrence and development are all real, there are some things that cause and effect is a kind of inevitable. But in the music creation, imagine whether can get rid of the shackles of reality and authenticity, it can get rid of reality to an "ideal" virtual space. (3) In the process of imagination, and limitless is one of the main feature of it. The creation of the imagination, unlike other factors to the main line and the content are confined to a small range. It can be infinite to think about it, we can even imagine more deeply the essence of comprehensive in literary creation.

Digital music is a digital format for storage, can on the Internet and wireless network transmission of music. Digital music has no longer rely on the material carrier, transmission speed, download and upload way widely and format variety, low loss of sound quality, and easy to operate and processing, etc. These characteristics of the digital music determines it has obvious advantages compared with traditional music, therefore, digital music has received the attention of the general government and enterprises, to develop the digital music industry. Cloud computing is known as primary global most anticipated technology revolution, and the cloud is widespread worldwide attention, because it marks, not just a new technology, or caused by technology of the industry of a transformation, will determine the competitiveness of the country. Music cloud or music cloud is not a question of concept that has become the industry investment hot spots [1-4]. 
The development of an industry to get good, do not have enough profits to support is not possible. The current core digital music industry in China is lack of an effective business model to support the development of the industry, digital music producers can't fully ensure the reasonable interests of the above request. Without a stable profit model, contusion is not only the production of the digital music producers enthusiasm and passion, also may endanger the development of the industry, it is fatal blow for the industry. In the music copyright protection and industry profit these two pressures, whether can find a way of both, for the current China's digital music industry is imminent [5].

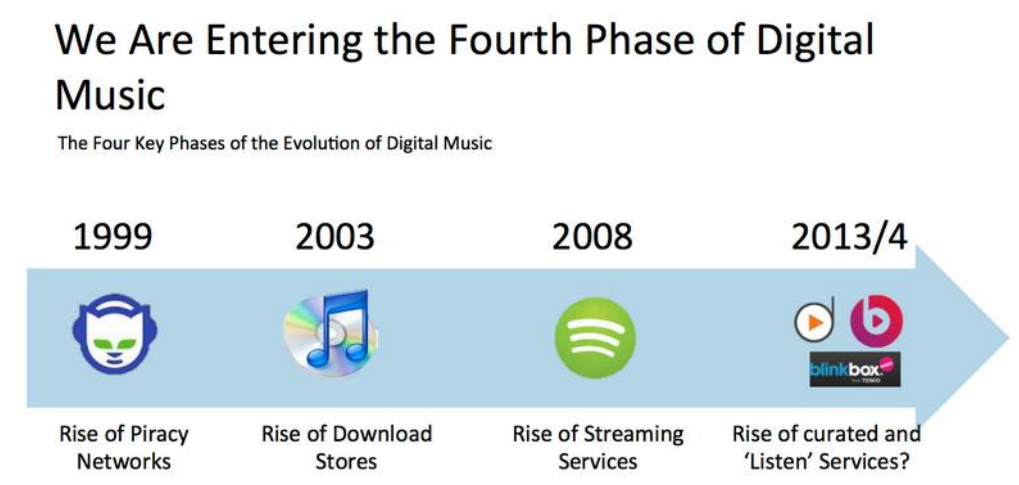

Figure 1. The Developmental Path of the Digital Music

In this paper, we conduct research on digital music generating model based on the music mapping and the visualization technology. Broader the concept of modern visualization technology, refers to is based on computer graphic technology, through the computer generated images of the general visual stimulation to the human body, so that the people to accept and understand the raw data, information, technology and methods. It as the cross subject covers many fields of research, including: computer graphics, computer vision, computer aided design, geometry, cognitive psychology and the primary human-computer interaction technology. Later, we will combine the technique of music mapping and the visualization to propose our novel pattern of digital music with theoretical analysis.

\section{Our Proposed Methodology}

The Digital Music and the Features. The rapid development of computer technology has made the computer into every aspect of our lives, music field is no exception. At present, the computer has become an indispensable tool in music production, and this new thing has entered the computer music in colleges and the universities music professional curriculum, and become a new applied branch discipline of musicology. At first, it is only as a means of making music, in the radio, television, movies and other commercial music and is widely used in commercial activities. Today, the computer music in music education has been increasingly prominent in the position, especially in the teaching of music theory, shows its important value and incomparable superiority. How to combine traditional music theory class teaching combined with advanced computer music production technology that has become an important subject music theory teaching reform [6-7].

As the application scenarios of digital music in universities, we could summarize them as follows. (1) Digital music lies in its use of the advantages of modern information processing technology, will sound well preserved at the same time, strengthen the music sound effect, makes the music more appealing, low degree of great improve the quality of the music sound and 
digital music technology adopted by the MIDI technology in radio, TV, film projector have also more involved and application. (2) Use of digital music technology reform is not of music education in colleges and universities of traditional music teaching pattern totally negative, but in the traditional music teaching advantages on the basis of proper improvement and perfection. (3) Theory by way of collective teaching and change the topic, and teachers as the leading factor, to teach the students about music technique theory, the teaching process should pay attention to student's guidance, inspiration and demonstration.

In the traditional teaching mode, only the score and want to hear specific acoustics effect is not easy, and use the computer make music MIDI system is different, it consists of a system to realize the composing, playing, making the whole process. In many cases, music production process is done by a person independent, composing and playing almost simultaneously, often is the playing of music written is over, but it also is only the first step. You can use the computer music of the creation system function and method for concrete production, fully shows its unique advantages. The appearance of computer music and the development of music art and voice processing technology is a revolution, it changed the traditional concept of music creation, playing and making way, to finally realize more music works to meet the social development demand for music on the quantity and quality.

The Music Mapping. Music playing is synchronized with the score of psychological thinking called heart music spectrum. It is time to perfect score suggests, improve the basic quality of playing, thinking necessary to create artistic charm of psychological language activities. Heart spectrum like music can record. If the score is the standards followed by the music playing, so heart spectrum is the psychological activity of thinking followed in the general play of standard while it can be for music performance required by the various types of the design respectively and explanation, brief acronyms, pictographic graphic, mark clew and method integrated five tips, and eventually become a conscious action of logic to think things as shown in the following figure.

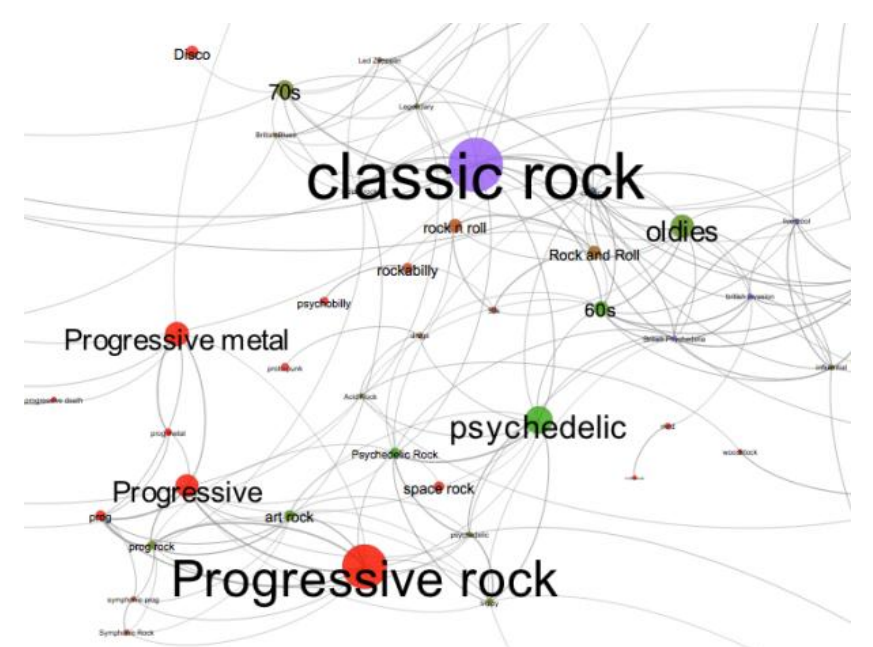

Figure 2. The Demonstration of the Music Mapping

Music is the music symbols recorded on paper carrier such as a form of literature. Said the music composer's mind that want to rely on particular pitch, intensity, duration and rhythm notation symbol record permutation and combination according to certain rules, as a result of its record music so, a notation symbol is music literature characteristic of the information symbols. The purpose of human invention notation symbol as is not limited to the record conception in the musician's music image but also is to let others can understand and reproduce and appreciation of the image.

Due to the limitations of spectrum surface markers, the level of there will be differences in the performance and simplified. To improve the level, it is difficult to find the answer in the sheet music, can only rely on experience, auditory memory to contrast analysis, ponder the performer mentality feeling over time, found that the performers in addition to a music in your heart, and accompanied by music and exist a set 
of the relevant control play state of thinking clues as spectrum phenomenon.

The Visualization Technology. The development of science and technology, especially the rapid development of computer technology, make human production capacity and to improve technology of large data in the face of a lot of information data, through the analysis of the human hard to effectively complete mastery of the whole data and cognition, therefore need all kinds of information technology to complete understanding of the task, and able to take advantage of its advanced technology for large amounts of information integration. This is based on the background the visualization technology has been extremely fast development and the importance to it. It can bring a lot of effective information data integration, and then through the computer technology to simulate the image or general dynamic information reference for people to use. Data from a certain sense, the most relevant information will hide their important data, the implicit information of data on people's correct use of these data have very important influence and role, so be sure to form a certain rule, using scientific and effective way to its visualization and give full play to its effectiveness [8].

Generally, the visualization process could be separated into the listed aspects. (1) Data preparation. Data preparation phase visual's goal was to make the function of data preprocessing in the form of the visualization and installation requirements for the raw data is handled in the process of a visual form. (2) Model generation. Model generation phase goal is to create the whole details presented in a visual form. Training set, model selection, parameter setting, the details of the training process, the result of the storage is the phase of the work. (3) Use the knowledge. The visualization of the targets is through the data mining process results in the form of visual, thus helping to acquire knowledge. In most cases, the results of data mining algorithms such as association, classification, etc., are a form of the human visual system is very difficult to understand. (4) Flow of the visualization, data mining process visual goal was to make the whole process of data mining in the form of a visual display in front of the user as also can give knowledge, an analyst with more confidence to guide the work of the next step. Accordingly, the visualization methods could be summarized as the follows.

- The pie chart. The pie chart shows information of all kinds of distribution of total share. The values of discrete fields as each slice of the pie chart, the value of the continuous in each discrete group summary on the value of the field. Circle diagram is a variation of the pie chart, can compare multiple continuous distribution of the value of the field at the same time.

- Box figure. Through the analysis of the measurement, the measurement and the variability of center value distribution measurement can understand the field values of descriptive statistics. Box figure is a variety of histogram, visually shows a continuous field of statistics.

- Histogram. Map shows the discrete, non-numeric type field values in the data set number and proportion. Distribution of a typical use is to reflect the imbalance of data. Histogram is also called frequency chart, is the way with a graphic display of the different values in the data set number which is also used to reveal the imbalance of data.

The Optimized Musical Creation Mode. Using computer programming language processing and create all kinds of sound and voice information technique. Algorithm creation can be said to be more pure computer music creation, the creation process is implemented by a programming language. And the creative process is not in music creation of traditional logic as the main reference system and the thinking, but with the logic of computer programming language and thinking as the main 
reference, it brings infinite randomness and creativity, sound organization and structure bring brand-new music organization technical means and forms, also bring the same as the traditional sound cognition is not the new stereo aesthetic evaluation [9].

Traditional music is concentrated in the basic melody, harmony, counterpoint, texture, instruments, strength, density, structure and the other elements and integrated, usually can be observed through the music analysis and research to meet its shape. In the digital environment, traditional music tend to be more as a whole or four items and the fuzzy concepts to comprehensive thinking, not in the traditional logic, systematic, functional, systematic to handle some independent elements separately. Some electronic features strong music works, audio to a certain extent, had the very big change. Understand to depend entirely on the observations of music score, but more to go through the spectrum analysis of sound, and ways to control data observation and it will take more than to depend on the actual sound auditory perception and verify its sound results.

Above no matter use what means to interaction of music creation, have a common characteristic: music creation is not written by a composer, there are quite a few components are random trigger in interactive performance as well as by the composers and performers of random response. Complete works of music is not a score, but has the four dimensions in the time dimension in the multimedia display and participation behavior of the space, the behavior itself is an indispensable part of content, creation is the process of creation, is also the result of the creation. Every result of the same, this is new technology media influence a distinctive characteristics of music creation. China's music needs in all aspects such as material, system, concept fully absorb and draw the lessons from the successful experience of the world's peoples and outstanding achievements, thus to keep up with the pace of the development of basic world civilization. Modern development does not lead to the disappearance of traditional folk music it will get to carry forward and lead to diversity of music aesthetic development.

\section{Conclusion}

In this paper, we conduct research on digital music generating model based on the music mapping and the visualization technology. Literature and art form is varied, want to, for example, just want to in the form of literature, drama art and so on. The art form has its inherent artistic image the composition of the image is from the subjective to give its people. We can understand so human subjective for the creation of artistic image has given art has the objective image. We studied music image usually is also a kind of artistic image, it and other artistic image, are the objective reflection of the external things. Music image and other artistic image difference is that the form depends on the existence of the voice, when the voice expressed by certain rules to make up the image of music. Under this basic background, we propose the music mapping and visualization based digital music generating model that will enhance the performance of the traditional creation paradigm.

\section{References}

[1] Krause, Amanda E., and David J. Hargreaves. "myTunes: Digital music library users and their self-images." Psychology of Music 41.5 (2013): 531-544.

[2] Danaher, Brett, et al. "The Effect of Graduated Response Anti - Piracy Laws on Music Sales: Evidence from an Event Study in France." The Journal of Industrial Economics 62.3 (2014): 541-553.

[3] Rangarajan, Rohit. "Generating music from natural language text." Digital Information Management (ICDIM), 2015 Tenth International Conference on. IEEE, 2015. 
[4] Salunke, D. B., and R. S. Kawitkar. "Analysis of LMS, NLMS and MUSIC Algorithms for Adaptive Array Antenna System." International Journal of Engineering and Advanced Technology (IJEAT) 2 (2013): 130-133.

[5] Ilie, Gabriela, and Ramen Rehana. "Effects of Individual Music Playing and Music Listening on Acute-Stress Recovery Les effets du jeu et de l'écoute musicale sur le rétablissement d'un individu a la suite d'un stress aigu." Canadian Journal of Music Therapy 19.1 (2013): 23.

[6] Schedl, Markus, Emilia Gómez, and Masataka Goto. "Multimedia information retrieval: music and audio." Proceedings of the 21st ACM international conference on Multimedia. ACM, 2013.

[7] Lee, Jin Ha, and Sally Jo Cunningham. "The Impact (or Non-impact) of User Studies in Music Information Retrieval." ISMIR. 2012.

[8] Hyung, Ziwon, Kibeom Lee, and Kyogu Lee. "Music recommendation using text analysis on song requests to radio stations." Expert Systems with Applications 41.5 (2014): 2608-2618.

[9] Rae-Hunter, Casey. "Better Mousetraps: Licensing, Access, and Innovation in the New Music Marketplace." J. Bus. \& Tech. L. 7 (2012): 35 . 